\title{
Structural and Spectroscopic Investigation of Ceria Nanofibers Fabricated by Electrospinning Process
}

\author{
Ah Reum Hwang, Juyun Park, and Yong-Cheol Kang* \\ Department of Chemistry, Pukyong National University, Busan 608-737, Korea. *E-mail: yckang@pknu.ac.kr \\ Received June 16, 2011, Accepted July 25, 2011
}

\begin{abstract}
We fabricated ceria $\left(\mathrm{CeO}_{2}\right)$ nanofibers by applying a mixed solution of polyvinylpyrrolidone (PVP) and various concentrations of cerium nitrate hydrate $\left(\mathrm{Ce}\left(\mathrm{NO}_{3}\right)_{3}\right)$ ranging from 15.0 to 26.0 wt \% by the electrospinning process. Ceria nanofibers were obtained after calcining $\mathrm{PVP} / \mathrm{Ce}\left(\mathrm{NO}_{3}\right)_{3}$ nanofiber composites at 873 and $1173 \mathrm{~K}$. The SEM images indicated that the diameters of $\mathrm{CeO}_{2}$ nanofibers calcined at 873 and 1173 $\mathrm{K}$ were smaller than those of nanofibers obtained at RT. As the amount of cerium increased, the diameter of $\mathrm{CeO}_{2}$ nanofibers increased. XRD analysis revealed that the ceria nanofibers were in cubic form. TEM results revealed that the ceria nanofibers were formed by the interconnection of Ce oxide nanoparticles. The ceria nanofibers obtained at low concentrations of $\mathrm{Ce}(\mathrm{CeL})$ showed spotty ring patterns indicated that the ceria nanofibers were polycrystalline structure. And the ceria nanofibers obtained at high concentration of $\mathrm{Ce}(\mathrm{CeH})$ showed fcc (001) diffraction pattern. XPS study indicated that the oxidation of Ce shifted from $\mathrm{Ce}^{3+}$ to $\mathrm{Ce}^{4+}$ as the calcination temperature increased.
\end{abstract}

Key Words : Ceria, Nanofiber, XPS, TEM

\section{Introduction}

Recently, nanotechnology has been a big issue throughout the science community. Production of nanofibers is considered as a part of nanotechnology. Electrospinning has been used as a simple and useful method for synthesizing nanosized materials such as nanomats, ${ }^{1}$ nanobelts, ${ }^{2}$ nanospring, ${ }^{3}$ and nanofibers. ${ }^{4}$ This technique creates a high specific surface area to volume ratio, high porosity and continuous fibers. ${ }^{5}$ Nanofibers have various applications including textile devices, ${ }^{6,7}$ catalysts, ${ }^{8,9}$ membranes, ${ }^{10}$ sensors, ${ }^{11}$ biomedical applications, ${ }^{7,12}$ and filtration. ${ }^{11-14}$ The combination of sol-gel and electrospinning process is the most promising technology for the fabrication of nanofibers. ${ }^{15}$

Nano-sized $\mathrm{CeO}_{2}$ is used in many applications like cosmetic materials, high-storage capacitor devices, ${ }^{16}$ buffer layers for conductors, ${ }^{17-19}$ fuel cells, ${ }^{20,21}$ and optical devices. ${ }^{22-24}$ Also cerium dioxide has been popularly used in automotive catalysts $^{16,25}$ because of its unique characteristic of $\mathrm{Ce}$ (IV) and Ce (III) converting to one another. ${ }^{26}$

Barreca et al. studied the oxidation states of $\mathrm{Ce}$ in $\mathrm{CeO}_{2}$ thin films obtained by plasma-enhanced chemical vapor deposition (PECVD) using XPS. ${ }^{17}$ They showed that the obtained $\mathrm{CeO}_{2-x}$ films had a tunable $\mathrm{Ce}^{4+} / \mathrm{Ce}^{3+}$ ratio as a function of the substrate temperature or the $\mathrm{O}_{2}$ partial pressure. Muroga et al. investigated $\mathrm{CeO}_{2}$ thin films, which are deposited by pulsed laser deposition method on $\mathrm{Gd}_{2} \mathrm{Zr}_{2} \mathrm{O}_{7}$ tapes, by means of SEM and TEM. ${ }^{18}$ They revealed that the degree of grain alignment improved as the thickness of $\mathrm{CeO}_{2}$ film increased. Kanakaraju et al. focused on the optical and structural properties of $\mathrm{CeO}_{2}$ films. The films were deposited through reactive ion beam sputtering technique at different substrate temperatures and oxygen partial pressures. ${ }^{23}$
According to their XRD study, more crystalline phases of $\mathrm{CeO}_{2}$ were observed as the substrate temperature increased up to $500{ }^{\circ} \mathrm{C}$. The tetravalent $\mathrm{Ce}$ with three different final states was observed in $\mathrm{CeO}_{2}$ films by radio frequency magnetron sputtering method. ${ }^{24}$

Structural and spectroscopic investigations of Ce oxide nanofibers were very sparse to our knowledge. In this study, we fabricated $\mathrm{Ce}$ oxide nanofiber composites with different cerium concentrations applying sol-gel and the electrospinning process. The obtained nanofiber composites were calcined at 873 and $1173 \mathrm{~K}$ in order to manipulate the ratio of $\mathrm{Ce}(\mathrm{IV})$ to $\mathrm{Ce}$ (III) for obtaining the desired physical and chemical properties. And the synthesized cerium oxide nanofibers were characterized by scanning electron microscopy (SEM), X-ray diffraction (XRD), transmission electron microscopy (TEM), and X-ray photoelectron spectroscopy (XPS).

\section{Experimental}

Two different concentrations of Ce solutions were applied to fabricate $\mathrm{Ce}$ oxide nanofibers. The low concentration (denotes as CeL, $15.0 \mathrm{wt} \%$ of $\mathrm{Ce}$ ) was obtained by dissolving $0.11 \mathrm{~g}$ of $\mathrm{Ce}\left(\mathrm{NO}_{3}\right)_{3} \cdot 6 \mathrm{H}_{2} \mathrm{O}$ and $0.62 \mathrm{~g}$ of polyvinylpyrrlidone (PVP) in the mixed solvent of $2 \mathrm{~mL}$ of distilled water and $10 \mathrm{~mL}$ of ethyl alcohol. And the solution was stirred for $12 \mathrm{hrs}$ at room temperature. The high $(\mathrm{CeH}, 26.0$ wt \%) concentration of cerium nitrate solutions was made with $0.22 \mathrm{~g}$ of $\mathrm{Ce}\left(\mathrm{NO}_{3}\right)_{3} \cdot 6 \mathrm{H}_{2} \mathrm{O}$ powder. And other conditions were kept the same as the preparation of the CeL viscous solution. The viscosity of the solution was measured by using a viscometer (SV-10, A\&D, Japan) and the viscosities of each solution were 65.1 and $68.7 \mathrm{cP}$ for $\mathrm{CeL}$ and $\mathrm{CeH}$, 
respectively. Cerium(III) nitrate hexahydrate $\left(\mathrm{Ce}\left(\mathrm{NO}_{3}\right)_{3} \cdot 6 \mathrm{H}_{2} \mathrm{O}\right.$, 99\%) and PVP (MW: 1,300,000) were purchased from Aldrich. Ethyl alcohol (99.9\% pure) was purchased from Burdick \& Jackson.

In order to fabricate the Ce nanofibers, the viscous solutions were transferred into a $10 \mathrm{~mL}$ plastic syringe with a 22 gauge of metal needle and was delivered at a constant flow rate $(15-16 \mu \mathrm{L} / \mathrm{min})$ using a syringe pump (KDS scientific). The $0.41 \mathrm{kV} / \mathrm{cm}$ of electrical field was employed between the needle and a drum collector, which was covered with aluminum foil, to obtain Ce oxide nanofibers. The collector was rotating at a constant speed of $100 \mathrm{rpm}$. The obtained nanofiber composites were calcined at two different temperatures: 873 and $1173 \mathrm{~K}$, which were chosen by the results of thermogravimetric analysis in our previous research. ${ }^{27}$

The morphology and the size of obtained nanofibers were determined by SEM (JEOL, JSM-6700F, Japan). In order to identify the crystal structure of the obtained nanofibers, XRD (PHILIPS, X'Pert-MPD, Netherlands) analysis was performed with $3 \mathrm{~kW}$ of $\mathrm{Cu}$ X-ray source. Data were collected from 10 to 80 degrees with a scanning speed of 3 degrees/min and the step size was $0.05^{\circ}$. TEM (JEOL, JEM2010 , Japan) analysis was performed to verify the crystallinity of the obtained nanofibers after calcining at $1173 \mathrm{~K}$. The XPS (VG MultiLab 2000, UK) was carried out for investigation of the chemical nature of the Ce oxide nanofibers. The source of X-ray was $\mathrm{Mg} \mathrm{K \alpha}(1253.6 \mathrm{eV})$ and the base pressure of XPS chamber was kept at around $1 \times 10^{-10}$ Torr. The survey XP spectra were taken at $50 \mathrm{eV}$ of constant analyzer energy (CAE) mode with $0.5 \mathrm{eV}$ of energy step size. High resolution XP spectra such as $\mathrm{Ce} 3 \mathrm{~d}, \mathrm{O} 1 \mathrm{~s}$ and $\mathrm{C}$ $1 \mathrm{~s}$ were taken at $20 \mathrm{eV}$ of CAE and $0.02 \mathrm{eV}$ of energy step size. And other parameters were kept the same as the survey scan.

\section{Result and Discussion}

SEM Analysis. Figure 1 shows the SEM images of $\mathrm{CeH}$ and CeL nanofibers obtained at RT (denoted as CeH-RT and CeL-RT, respectively) after calcining at two different temperatures: 873 (CeH-873 and CeL-873) and $1173 \mathrm{~K}$ (CeH-1173 and CeL-1173). The surfaces of CeH-RT and CeL-RT were found to be smooth and uniform. After calcination was performed at $873 \mathrm{~K}$, the rough surface of nanofibers was observed and the diameter had decreased. When the higher calcinations temperature $(1173 \mathrm{~K})$ was applied to the Ce nanofibers, small pores in the nanofibers

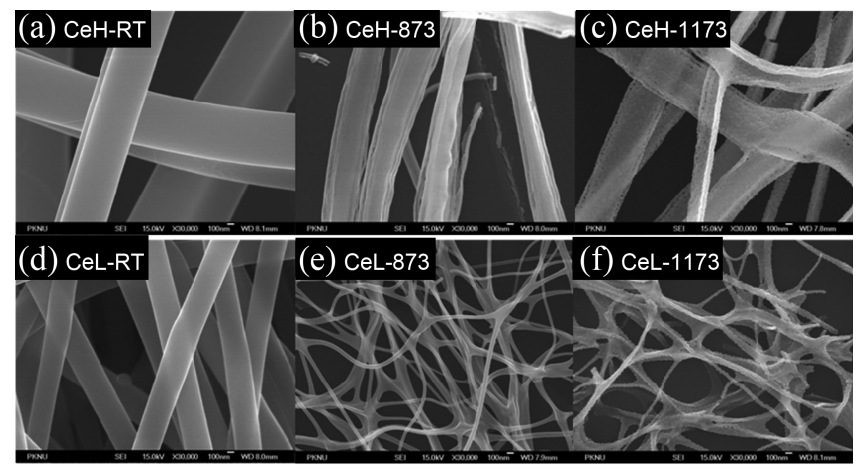

Figure 1. SEM images of $\mathrm{PVP} / \mathrm{Ce}\left(\mathrm{NO}_{3}\right)_{3}$ nanofibers obtained at different calcination temperatures with different concentrations of cerium nitrate: $\mathrm{CeL}(15.0 \%)$ and $\mathrm{CeH}(26.0 \%)$.

formed. The decrease in diameter and the formation of pores are mainly due to the decomposition and removal of PVP and evaporation of water and nitrate group during calcination process. The diameter of CeL-1173 was decreased down to $13 \%$ of CeL-RT and nanofibers were stuck to form nano-sized mats. This implies that the composition ratio of PVP is greater than that of Ce in CeL-RT nanofibers. The diameter of $\mathrm{CeH}$ nanofibers, however, did not change as much as $\mathrm{CeL}$ reduced by increasing the calcination temperature. The $\mathrm{Ce}$ in $\mathrm{CeH}$ nanofibers might be a role as scaffolds of the nanofibers. It is worthy to note that the relative ratio of Ce to PVP was determined by the pathway of the formation of $\mathrm{Ce}$ oxide nanofibers. At low $\mathrm{Ce}$ ratio, the nanofibers diameter reduced remarkably because of the high composition of PVP which is decomposed and evaporated after calcinations. Pore formation was observed in $\mathrm{CeH}$ without reducing the diameter considerably because the high compositional ratio of $\mathrm{Ce}$ roles as backbone of the nanofiber. The measured mean diameters of $\mathrm{Ce}$ nanofibers are shown in Table 1. As the calcination temperature increased, the diameters of nanofibers decreased and/or pores formed.

XRD Analysis. The XRD patterns of the Ce oxide nanofibers obtained at RT and after calcination with various concentrations are shown in Figure 2. No peaks were observed from nanofibers at RT regardless of the concentration of cerium nitrate. This indicates that nanofibers obtained at RT by the electrospinning technique are amorphous. ${ }^{27}$ After calcinations applied to the nanofibers, the cubic $\mathrm{CeO}_{2}$ diffraction peaks appeared. ${ }^{28}$ As the calcination temperature increased, more peaks evolved and the intensity increased as well. Comparing $\mathrm{CeL}$ and $\mathrm{CeH}$, the more concentrated the

Table 1. Diameter and crystal size of $\mathrm{CeL}$ and $\mathrm{CeH}$ nanofibers with respect to different calcination temperature. Diameter was measured from SEM images and crystal size was obtained from XRD patterns using Scherrer's formula

\begin{tabular}{ccccc}
\hline & & RT & $873 \mathrm{~K}$ & $1173 \mathrm{~K}$ \\
\hline \multirow{2}{*}{$\mathrm{CeL}$} & Diameter $(\mathrm{nm})$ & $375.03( \pm 30.07)$ & $54.68( \pm 7.38)$ & $47.20( \pm 19.91)$ \\
& Crystal size $(\mathrm{nm})$ & - & 11.19 & 47.54 \\
\hline \multirow{2}{*}{$\mathrm{CeH}$} & Diameter $(\mathrm{nm})$ & $741.08( \pm 80.79)$ & $382.42( \pm 76.77)$ & $611.61( \pm 78.88)$ \\
& Crystal size $(\mathrm{nm})$ & - & 12.39 & 49.41 \\
\hline
\end{tabular}




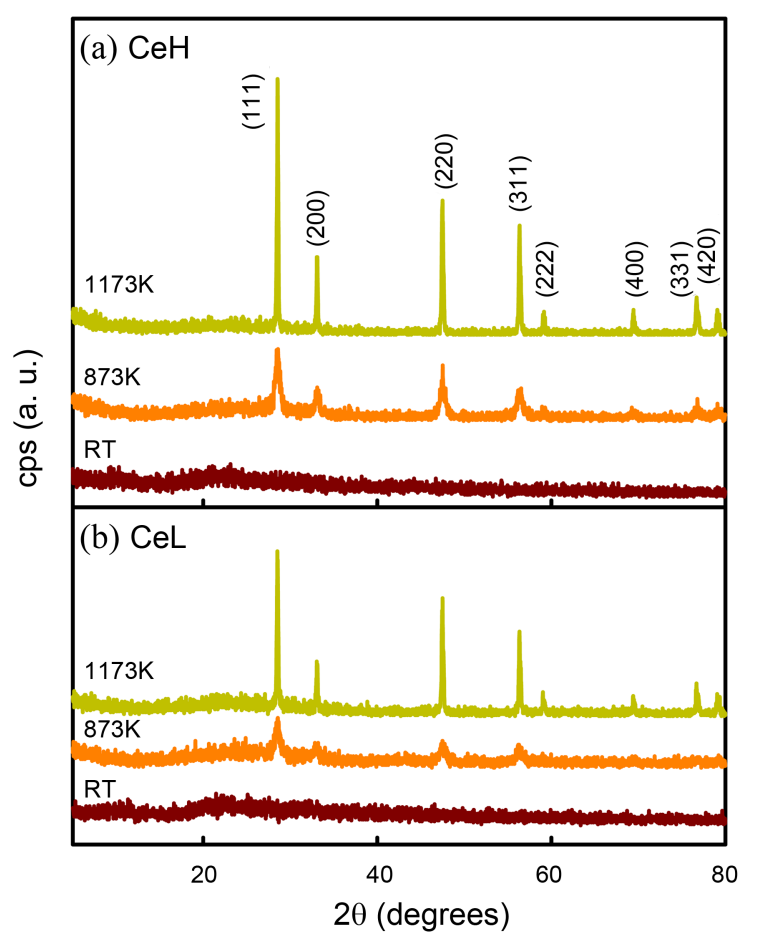

Figure 2. XRD patterns obtained from (a) $\mathrm{CeH}$ and (b) CeL nanofibers. All peaks present here are cubic $\mathrm{CeO}_{2}$ peaks.

Ce solution was, the more evolved diffraction peaks were observed, which was expected. The crystal size of cubic $\mathrm{CeO}_{2}$ obtained after calcining at $1173 \mathrm{~K}$ was calculated by using Scherrer's formula, $D_{p}=(0.94 \lambda) /(0.5 \beta \cos \theta)$, where $\lambda$ is the wavelength of $\mathrm{X}$-ray source, $\beta$ is the full width at the half maximum of a (111) peak, and $\theta$ is Bragg's diffraction angle. The obtained crystal size is shown in Table 1. The crystal size increased as the calcination temperature and the concentration of $\mathrm{Ce}$ increased.

TEM Analysis. The concrete crystallinity of Ce oxide nanofibers was examined with TEM and the images are shown in Figure 3. The ceria nanofibers were composed of nanoparticles with the average size of $c a .50 \mathrm{~nm}$ and nanosized pores were observed as well shown in the insets. These small nanoparticles are mutually interconnected to form nanofibers and the resulted surface of Ce nanofiber was rough. Lattice patterns were observed and shown in upper parts of each image. The average lattice distances were measured with the Motic Images Plus 2.0ML program and the results are agrees with the reported values of d-spacing of cubic $\mathrm{CeO}_{2}$ (111) plane. ${ }^{29}$ Selected area electron diffraction (SAED) patterns of CeL-1173 and CeH-1173 nanofibers are shown at the bottom of each image. CeL-1173 showed spotty ring patterns indicating that polycrystalline fcc structure formed in CeL-1173. Clear fcc (001) pattern was observed at $\mathrm{CeH}-1173$ with high crystallinity. The ratio of zone axes $\mathrm{A} / \mathrm{B}$ was 1.4 which matched well with the theoretical value for fcc (001). These results are well cross supported with XRD data. As the amount of cerium increased in the nanofibers, more crystallinity was observed and the intensity of peaks increased.
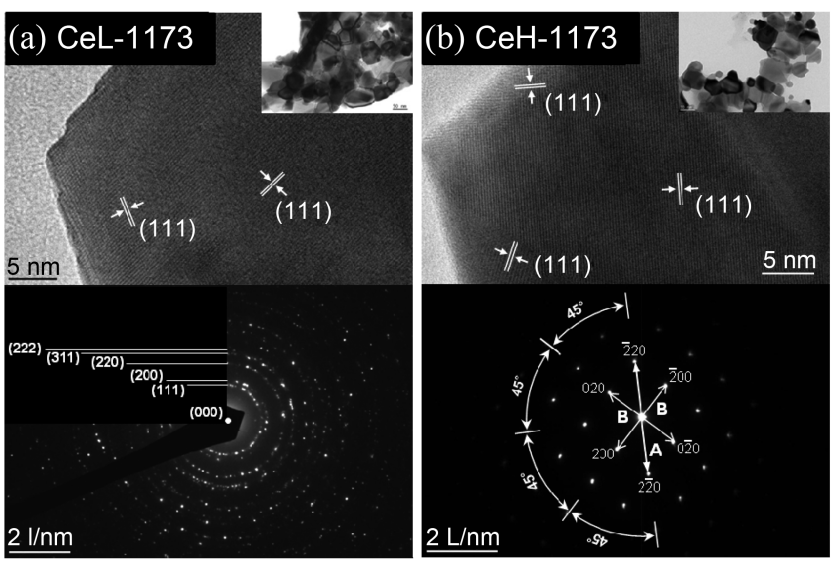

Figure 3. TEM images of (a) CeL-1173 and (b) CeH-1173 nanofibers. Top images show lattice pattern obtained from the insets of each image (scale bar $=50 \mathrm{~nm}$ ) and the bottom images depict selected area diffraction patterns. Zone axes (A and B) are added in the bottom image of c) for clarity.

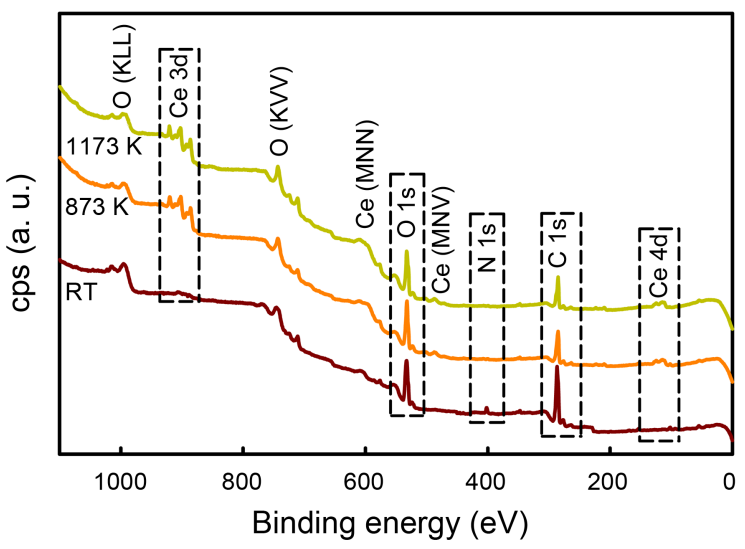

Figure 4. $\mathrm{XP}$ survey spectra of $\mathrm{CeH}$ nanofibers calcined at different temperatures.

XPS Analysis. The survey XP spectra of $\mathrm{CeH}$ nanofibers were shown in Figure 4. As the calcination temperature increased, Ce $3 \mathrm{~d}$ and $4 \mathrm{~d}$ peaks were pronounced. However the intensity of $\mathrm{C} 1 \mathrm{~s}$ decreased and the $\mathrm{N} 1 \mathrm{~s}$ peak was not detectable in CeH-873. The decomposition of PVP was confirmed by decreasing the intensity of $\mathrm{C} 1 \mathrm{~s}$ and $\mathrm{N} 1 \mathrm{~s}$ disappearing which were generated from PVP. Because of the decomposition of PVP, the ratio of $\mathrm{Ce}$ in calcined nanofibers was higher than that of CeH-RT. No other peaks except the peaks related with the elements in PVP and Ce are observed, so the feasibility of the fabrication of Ce oxide nanofibers by sol-gel and the electrospinning method is verified by XPS analysis.

More chemical information of $\mathrm{C} 1 \mathrm{~s}$ and $\mathrm{O} 1 \mathrm{~s}$ was obtained from high resolution XP spectra shown in Figure 5. In PVP, four chemically different carbons existed and were assigned as $\mathrm{C} 1(\mathrm{C}=\mathrm{O}), \mathrm{C} 2(\mathrm{C}-\mathrm{N}), \mathrm{C} 3(\mathrm{C}-\mathrm{C}=\mathrm{O})$, and $\mathrm{C} 4(\mathrm{C}-\mathrm{C})$. These matched with 4 deconvoluted peaks of $\mathrm{C} 1 \mathrm{~s}$ in $\mathrm{CeH}$ nanofibers from high to low binding energy. The atomic ratio of $\mathrm{C} 1: \mathrm{C} 2: \mathrm{C} 3: \mathrm{C} 4$ in PVP is 1:2:1:2. The atomic ratio in CeH-RT was almost the same as the ratio of pure PVP within experi- 


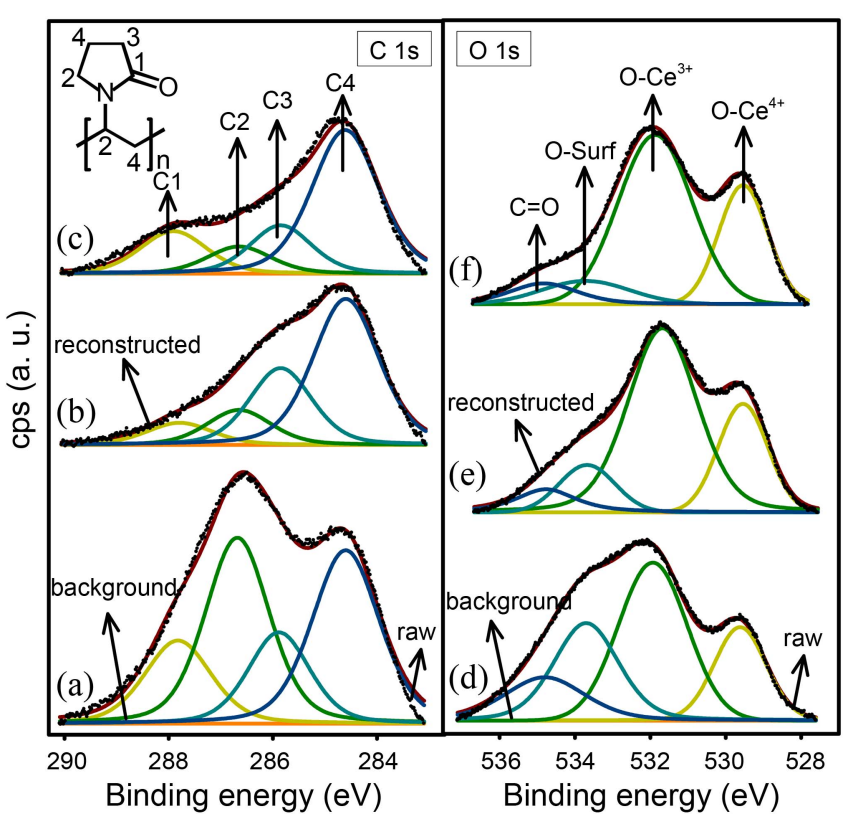

Figure 5. High resolution of XP spectra of $\mathrm{C} 1 \mathrm{~s}$ and $\mathrm{O} 1 \mathrm{~s}$ binding energy regions of $\mathrm{CeH}$ nanofibers; (a) and (d) for $\mathrm{CeH}-\mathrm{RT}$, (b) and (e) for CeH-873, and (c) and (f) for $\mathrm{CeH}-1173$. The molecular structure of PVP is shown in upper side of $\mathrm{C} 1 \mathrm{~s}$ spectra.

mental error. When the calcination temperature increased to $1173 \mathrm{~K}, \mathrm{C} 1 \mathrm{~s}$ peaks decreased due to the decomposition of PVP. Among them the intensity of $\mathrm{C} 2$ peak significantly decreased. This confirms that the decomposition of PVP progressed. The high resolution $\mathrm{O} 1 \mathrm{~s}$ spectra of Ce oxide nanofibers were deconvoluted into four peaks: two oxygen species on the surface region (O-Surf.), ${ }^{30,31}$ oxygen moieties bound with $\mathrm{Ce}^{3+}\left(\mathrm{O}_{-}-\mathrm{Ce}^{3+}\right)$ and $\mathrm{Ce}^{4+}\left(\mathrm{O}-\mathrm{Ce}^{4+}\right)$. In $\mathrm{CeH}-873$, the amount of oxygen bound with $\mathrm{Ce}^{3+}$ and $\mathrm{Ce}^{4+}$ increased and that of surface oxygen decreased. Because the calcination causes the removal of surface oxygen, it is reasonable that the ratio of surface oxygen decreased. Further increase of calcination temperature, up to $1173 \mathrm{~K}$, the portion of O$\mathrm{Ce}^{4+}$ increased and the portion of $\mathrm{O}-\mathrm{Ce}^{3+}$ decreased. Therefore it is highly possible that calcination of $\mathrm{Ce}$ oxide nanofibers at high temperatures led to oxidize $\mathrm{Ce}$ from $\mathrm{Ce}^{3+}$ to $\mathrm{Ce}^{4+}$.

Figure 6 shows the deconvoluted high resolution XP spectra of $\mathrm{Ce} 3 \mathrm{~d}$ region. Among the transition metal oxides, Ce oxide is one of the metal oxides which has various final states due to hybridization of $\mathrm{Ce} 4 \mathrm{f}$ and $\mathrm{O} 1 \mathrm{~s}$ valence orbitals. ${ }^{31,32} \mathrm{Ce}$ has two characteristic oxidation states $(+3$ and +4$)$. The Ce $3 \mathrm{~d}$ core level spectra were deconvoluted to

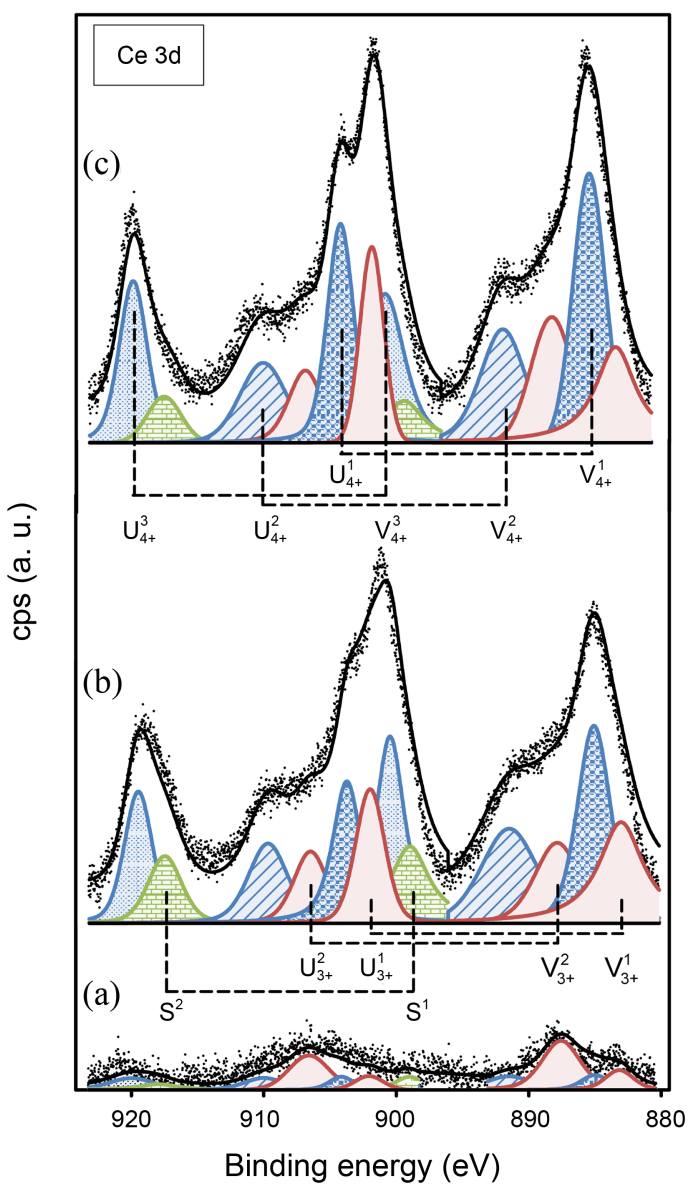

Figure 6. High resolution of XP spectra of Ce 3d binding energy regions of $\mathrm{CeH}$ nanofibers calcined at (a) RT, (b) $873 \mathrm{~K}$, and (c) $1173 \mathrm{~K} . \mathrm{V}$ is attributed to $3 \mathrm{~d}_{5 / 2}, \mathrm{U}$ is attributed to $3 \mathrm{~d}_{3 / 2}$ and $\mathrm{S}$ denotes satellite peak.

3 doublet peaks for $\mathrm{Ce}^{3+}$ and $\mathrm{Ce}^{4+}$ each. The initial state of $\mathrm{Ce}^{3+}$ is $3 \mathrm{~d}^{10} 4 \mathrm{f}^{1}$ and that of $\mathrm{Ce}^{4+}$ is $3 \mathrm{~d}^{10} 4 \mathrm{f}^{0}$. Three final states were assigned for $\mathrm{Ce}^{3+}$ and $\mathrm{Ce}^{4+}$ species each. The deconvoluted 6 doublet peaks of $\mathrm{Ce} 3 \mathrm{~d}$ spectra had a relatively similar spin-orbit splitting value of $18.65 \pm 0.16 \mathrm{eV}$. In this paper, $\mathrm{U}$ and $\mathrm{V}$ notations are used for the assignment of $\mathrm{Ce}$ $3 \mathrm{~d}$ corresponding to $3 \mathrm{~d}_{3 / 2}$ and $3 \mathrm{~d}_{5 / 2}$, respectively. The subscripts of $\mathrm{U}$ and $\mathrm{V}$ corresponds to the oxidation state of $\mathrm{Ce}$ and the superscripts are arbitrary numbers to differentiate the peaks of each oxidation state ordering from low to high binding energy. The detailed peak parameters and the final states of Ce oxide nanofibers are shown in Table 2. In the $\mathrm{Ce}^{3+}$ species, $\mathrm{U}_{3+}^{1}-\mathrm{V}_{3+}^{1}$ are the shake down peaks, $\mathrm{U}_{3+}^{2}-\mathrm{V}_{3+}^{2}$ are the main peaks, and $\mathrm{S}^{1}-\mathrm{S}^{2}$ are additional shake up

Table 2. The parameters applied for deconvolution of the Ce $3 \mathrm{~d}$ XP spectra

\begin{tabular}{|c|c|c|c|c|c|c|c|c|c|c|c|c|}
\hline \multirow[b]{2}{*}{ Binding energy $(\mathrm{eV})$} & \multicolumn{6}{|c|}{$\mathrm{Ce}^{3+}$} & \multicolumn{6}{|c|}{$\mathrm{Ce}^{4+}$} \\
\hline & 883.7 & 902.5 & 888.4 & 907.2 & 899.7 & 918.2 & 885.8 & 904.6 & 892.2 & 910.2 & 901.2 & 920.2 \\
\hline Notation & $\mathrm{V}_{3+}^{1}$ & $\mathrm{U}_{3+}^{1}$ & $\mathrm{~V}_{3+}^{2}$ & $\mathrm{U}_{3+}^{2}$ & $S^{1}$ & $S^{2}$ & $\mathrm{~V}_{4+}^{1}$ & $\mathrm{U}_{4+}^{1}$ & $\mathrm{~V}_{4+}^{2}$ & $\mathrm{U}_{4+}^{2}$ & $\mathrm{~V}_{4+}^{3}$ & $\mathrm{U}_{4+}^{3}$ \\
\hline Initial state & \multicolumn{6}{|c|}{ Ce $3 d^{10} 4 f^{1}-O 2 p^{6}$} & \multicolumn{6}{|c|}{ Ce $3 d^{10} 4 f^{0}-O 2 p^{6}$} \\
\hline Final state & \multicolumn{2}{|c|}{ Ce $3 d^{9} 4 f^{2}-O 2 p^{5}$} & \multicolumn{2}{|c|}{ Ce $3 d^{9} 4 f^{1}-O 2 p^{6}$} & \multicolumn{2}{|c|}{ - } & \multicolumn{2}{|c|}{ Ce $3 d^{9} 4 f^{2}-O 2 p^{4}$} & \multicolumn{2}{|c|}{ Ce $3 d^{9} 4 f^{1}-O 2 p^{5}$} & \multicolumn{2}{|c|}{ Ce $3 d^{9} 4 f^{1}-O 2 p^{6}$} \\
\hline
\end{tabular}


satellite peaks adapted to fitting the raw data. ${ }^{32}$ In the $\mathrm{Ce}^{4+}$ moiety, two shake down peaks $\left(\mathrm{U}_{4+}^{1}-\mathrm{V}_{4+}^{1}\right.$ and $\left.\mathrm{U}_{4+}^{2}-\mathrm{V}_{4+}^{2}\right)$ were assigned and the main peaks $\left(\mathrm{U}_{4+}^{3+}-\mathrm{V}_{4+}^{3}\right)$ were the characteristic peaks of $\mathrm{Ce}^{4+}$. In $\mathrm{CeH}-\mathrm{RT}$, both $\mathrm{Ce}^{3+}$ and $\mathrm{Ce}^{4+}$ features were detected in $\mathrm{Ce} 3 \mathrm{~d}$ spectrum and $\mathrm{Ce}^{3+}$ was dominated. After Ce oxide nanofibers were calcined at 873 $\mathrm{K}$, the amount of $\mathrm{Ce}^{3+}$ and $\mathrm{Ce}^{4+}$ both increased remalkably. This phenomenon strongly supports the results observed in C 1s XP spectra that the decomposition of PVP occurred at $873 \mathrm{~K}$. However, predominant features changed to $\mathrm{Ce}^{4+}$. Further increase of calcination temperature to $1173 \mathrm{~K}$, showed us that the amount of $\mathrm{Ce}^{3+}$ decreased, while $\mathrm{Ce}^{4+}$ increased. This result indicates that the oxidation of Ce from +3 to +4 occurred during calcination of Ce oxide nanofibers. This behavior is also confirmed by $\mathrm{O} 1 \mathrm{~s}$ spectra in Figure 5 .

\section{Conclusion}

$\mathrm{PVP} / \mathrm{Ce}\left(\mathrm{NO}_{3}\right)_{3}$ composite nanofibers were successfully fabricated by using sol-gel and the electrospinning technique. And Ce oxide nanofibers were synthesized by calcining the composite nanofibers at 873 and $1173 \mathrm{~K}$. SEM images indicated that the diameter of $\mathrm{CeO}_{2}$ nanofibers decreased by increasing calcination temperature. As the amount of cerium increased, diameter of $\mathrm{CeO}_{2}$ nanofibers increased. XRD analysis revealed that the $\mathrm{PVP} / \mathrm{Ce}\left(\mathrm{NO}_{3}\right)_{3}$ nanofibers were amorphous and cubic $\mathrm{CeO}_{2}$ nanofibers formed after calcining at $873 \mathrm{~K}$. As the calcination temperature increased, the crystal size of $\mathrm{Ce}_{2} \mathrm{O}$ increased. The peak intensity increased with increase of the cerium nitrate concentration. TEM results revealed that the Ce oxide nanofibers were composed with nanoparticles. And spotty ring patterns $(\mathrm{CeL})$ indicated that the Ce oxide nanofibers were of a polycrystalline structure. And $\mathrm{CeH}$ diffraction pattern is fcc. XPS study indicated that as the calcination temperature increased, Ce $3 \mathrm{~d}$ peak evolved by removal of PVP at CeH-873. Further increase of calcination temperature resulted that the oxidation state of Ce shifted from $\mathrm{Ce}^{3+}$ to $\mathrm{Ce}^{4+}$. XP spectra of Ce $3 \mathrm{~d}$ and $\mathrm{O} 1 \mathrm{~s}$ revealed that the oxidation of $\mathrm{Ce}$ occurred during calcination of Ce nanofibers.

Acknowledgments. This research was supported by Basic Science Research Program through the National Research Foundation of Korea (NRF) funded by the Ministry of Education, Science and Technology (20100021332). The author YCK acknowledged to Jisoo Kang for proofreading.

\section{References}

1. Ashammakhi, N.; Ndreu, A.; Piras, A. M.; Nikkola, L.; Sindelar, T.; Ylikauppila, H.; Harlin, A.; Gomes, M. E.; Neves, N. M.; Chiellini, E.; Chiellini, F.; Hasirci, V.; Redl, H.; Reis, R. L. J.
Nanosci. Nanotechnol. 2007, 7, 862.

2. Yang, A.; Tao, X.; Pang, G. K. H.; Siu, K. G. G. J. Am. Ceram. Soc. 2008, $91,257$.

3. Chen, S.; Hau, H.; Hu, P.; Wendorff, J. H.; Greiner, A.; Agarwal, S. Macromol. Mater. Eng. 2009, 294, 781.

4. Chuangchote, S.; Supaphol, P. J. Nanosci. Nanotechnol. 2006, 6, 125 .

5. Luepong, K.; Koombhongse, P.; Kongkachuichay, P. Chiang Mai J. Sci. 2009, 37(1), 85.

6. Kang, M. S.; Jin, H. J. Key Engineering Materials 2006, 321, 934.

7. Bolgen, N.; Menceloglu, Y. Z.; Acatay, K.; Vargel, I.; Piskin, E. J. Biomater. Sci. Polymer Edn. 2005, 16, 1537.

8. Stasiak, M.; Roben, C.; Rosenberger, N.; Schleth, F.; Studer, A.; Greiner, A.; Wendorff, J. H. Polymer 2007, 48, 5208.

9. Stasiak, M.; Studer, A.; Greiner, A.; Wendorff, J. H. Eur. J. Inorg. Chem. 2007, 13, 6150.

10. Kim, S. J.; Nam, Y. S.; Rhee, D. M.; Park, H. S.; Park, W. H. European Polymer Journal 2007, 43, 3146.

11. Caricato, A. P.; Capone, S.; Ciccarella, G.; Martino, M.; Rella, R.; Romano, F.; Spadavecchia, J.; Taurino, A.; Tunno, T.; Valerini, D. Applied Surface Science 2007, 253, 7937.

12. Wang, Y.; Yang, Q.; Shan, G.; Wang, C.; Du, J.; Wang, S.; Li, Y.; Chen, X.; Jing, X.; Wei, Y. Materials Letter 2005, 59, 3046.

13. Maze, B.; Vahedi Tafreshi, H.; Wang, Q.; Pourdeyhimi, B. Aerosol Science 2007, 38, 550.

14. Gopal, R.; Kaur, S.; Ma, Z.; Chan, C.; Ramakrishna, S.; Matsuura, T. J. Memb. Sci. 2007, 281, 581.

15. Ramaseshan, R.; Sundarrajan, S.; Jose, R.; Ramakrishna, S. J. Appl. Phys. 2007, 102, 111101

16. Namai, Y.; Fukui, K. I.; Iwasawa, Y. J. Phys. Chem. B 2003, 107, 11666.

17. Barreca, D.; Gasparotto, A.; Tondello, E.; Sada, C.; Polizzi, S.; Benedetti, A. Chem. Vap. Depos. 2003, 9, 199.

18. Muroga, T.; Iwai, H.; Yamada, Y.; Izumi, T.; Shiohara, Y.; Iijima, Y.; Saito, T.; Kato, T.; Sugawara, Y.; Hirayama, T. Physica. C 2003, 796, 392.

19. Shirakawa, M.; Unno, J.; Aizawa, K.; Kusunoki, M.; Mukaida, M.; Ohshima, S. Physica. C 2003, 1346, 392.

20. Kleinlogel, C.; Gauckler, L. J. Adv. Mater. 2001, 13, 1081.

21. Kendall, K.; Palin, M. J. Power Sources 1998, 71, 268.

22. Patsalas, P.; Logothetidis, S.; Metaxa, C. Appl. Phys. Lett. 2002, $81,466$.

23. Kanakaraju, S.; Mohan, S.; Sood, A. K. Thin Solid Films 1997, 305, 191 .

24. Guo, S.; Arwin, H.; Jacobson, S. N.; Jarrendahl, K.; Helmerson, U. J. Appl. Phys. 1995, 77, 5369.

25. Sohlberg, K.; Pantelides, S. T.; Pennycook, S. J. J. Am. Chem. Soc. 2001, 123, 6609.

26. Yang, X.; Shao, C.; Liu, Y.; Mu, R.; Guan, H. Thin Solid Films 2005, 478, 228.

27. Qizheng, C.; Xiangting, D.; Jinxian, W.; Mei, L. Journal of Rare Earths 2008, 26, 664.

28. JCPDS Database, International Center for Diffraction Data 1997, PDF 81-0792.

29. Kang, M.; Park, E. D.; Kim, J. M.; Yie, J. E. Appl. Catal. A 2007, 327, 261.

30. Yao, H. B.; Li, Y.; Wee, A. T. S. Appl. Surf. Sci. 2000, 158, 112.

31. Sohal, R.; Lupina, G.; Seifarth, O.; Zaumseil, P.; Walczyk, C.; Schroeder, T. Surf. Sci. 2010, 604, 276.

32. Bera, S.; Mittal, V. K.; Venkata Krishnan, R.; Saravanan, T.; Velmurugan, S.; Nagarajan, K.; Narasimhan, S. V. J. Nucl. Mat. 2009, 393, 120. 